\title{
The Impact of Marketing Mix Elements on Brand Loyalty towards Speech Therapy in Health Science Industry Malaysia
}

\author{
Masri bin Abdul Lasi, Tan Cheng Man* \\ City Graduates School, City University Malaysia, Kuala Lumpur, Malaysia \\ Email: masri.abdullasi@city.edu.my, „grace_cm91@hotmail.com
}

How to cite this paper: bin Abdul Lasi, M., \& Man, T. C. (2020). The Impact of Marketing Mix Elements on Brand Loyalty towards Speech Therapy in Health Science Industry Malaysia. American Journal of Industrial and Business Management, 10, 1575-1585.

https://doi.org/10.4236/ajibm.2020.109100

Received: August 11, 2020

Accepted: September 15, 2020

Published: September 18, 2020

Copyright $\odot 2020$ by author(s) and Scientific Research Publishing Inc. This work is licensed under the Creative Commons Attribution International License (CC BY 4.0).

http://creativecommons.org/licenses/by/4.0/

\begin{abstract}
Speech therapy is provided to clients, students or patients, depending on the setting of service delivery, when they are encountering feeding, speech and language (communication) and swallowing difficulties. Speech therapy service is a business-to-consumer (B2C) setting. However, this industry received low public awareness in Malaysia. With enhanced and right marketing strategy, it is believed to promote effective brand loyalty, including revisit of therapy service and repurchase of therapy product. This study aims to investigate the effectiveness of five different marketing strategies in building sustainable brand loyalty considering uniqueness of this industry. The strategies are conducting promotion about pricing structure (Price Promotion), conducting promotion about product content, brand personality, packaging and others (Product Promotion), conducting promotion at different places, including electronic platforms, newspaper and others (Place Promotion), bundling different pricing structure according to nature and type of different products (Product Price), informing customer regarding pricing about goods bundle, payment method, price flexibility and others through several distribution channels (Place Price). Data collection in this quantitative study was done by distributing self-designed questionnaires to 200 respondents. They are given Likert scale to measure the degree of brand loyalty result from different marketing mix. Data was analyzed using SPSS. The findings revealed that the marketing mix has a positive relationship with brand loyalty in speech therapy health science industry in Malaysia. In details, there is relationship between marketing mixture of Price Promotion, Product Promotion, Place Promotion, Product Price and Place Price, with the brand loyalty. It is recommended for future researcher to study the link between the number of service or product accessed with brand loyalty within similar constructs. It is also recommended to study the relationship between Customer Relationship Marketing (CRM) and Integrated Marketing Communication (IMC) with brand loyalty in speech therapy industry in Malaysia.
\end{abstract}




\section{Keywords}

Brand Loyalty, Health Science Malaysia, Marketing Mix, Speech Therapy

\section{Introduction}

Speech therapy is a type of therapy provided to population with feeding, communication and swallowing difficulties. The population can be paediatric and adult population. Communication problems can be categorized into speech problem (pronunciation problem, apraxia, resonance problem, voice problem, stuttering and others) and language problem (speech delay, difficult to follow command, difficulty to understand conversation and others). Swallowing problem can be in the form of having tube-feeding or alternate method of feeding, difficulty in swallowing food and/or drink, taking long time to finish a meal and others. The obligations of Speech Therapist can be differ depending on the setting of working place. Speech Therapist in hospital may see more cases with swallowing problem; Speech Therapist in school may see more cases with expressive language problem; Speech Therapist in private centre may see more cases with speech and language delay. Other than providing therapy directly to clients or patients, Speech Therapist educates public about the role of Speech Therapist, improves public awareness, trains caregivers, develops services standards, policies and procedures, and conduct research.

Speech therapy profession is indeed less known by the public in Malaysia, hence when graduates search for a job, they choose to rather be employed by a small company. Being professionally isolated makes them vulnerable and unable to create impact on the market due to low public awareness. Speech therapist's role is to improve feeding, communication and swallowing skills among paediatric and adult population. Hence, their workplace can vary, either school, centre or hospital settings.

Branding is crucial for a company's performance. It improves demands and directly boosts performance. This works the same for the health care industry. Speech therapy is one of the Allied Health Science. In Malaysia, the speech therapy industry is in its infant stage. There is high demand in Malaysia in fact according to iMoney Learning Centre (2016) - there is an approximation of 30,000 children with disabilities were registered in Malaysia in 2012.

According to statistics from Malaysian Association of Speech-Language and Hearing (MASH, 2020), in year 2020, in Kuala Lumpur, there are only 24 speech therapy centres available, highlighting low public awareness towards this industry. Thus, marketing is definitely required. Brand loyalty can keep more customers and reduce the customer who leave (Adel, 2015), and associate with self-brand connection and brand experience (van der Westhuizen, 2017). It directly influences company performance. Hence, to investigate the impact of marketing mix element is crucial to provide guidance to speech therapy centre owner in making a right marketing investment to promote brand loyalty. 
With enhanced detection and response towards cue from customer, centres are more capable to build a quality relationship with customer. Brand equity is crucial for increasing advertising efficiency and enable more purchase decision, other than brand differentiation (Davcik \& Sharma, 2015). With brand loyalty, there would be less brand-switch behaviour and more customer retention.

As for the scope of past research, the impact of marketing mix element is only done in mobile phone industry (Odoom, 2016; Jewel, Abubakar, Lucy, \& Samuel, 2018; Adel, 2015) and hotel service industry (Tanford, Shoemaker, \& Dinca, 2016). Limited research has been done to investigate the marketing mix element in health science industry, specifically speech therapy field. This restricts speech therapy centre owners in deciding their extent of marketing expenditure, amount of promotional activities and the overall marketing mechanism to build brand loyalty.

\section{Literature Review}

\subsection{Relationship between Marketing Mixture of Price Promotion and Brand Loyalty}

Speech therapy is provided to clients, students or patients, depending on the setting of service delivery, when they are encountering feeding, speech and language (communication) and swallowing difficulties; it is a business-to-consumer (B2C) setting. Therefore, marketing practitioner shall understand the customer-brand relationship (CBR) which involves brand loyalty, and which aspect of marketing to invest on is much relatively important to ensure a wise marketing investment.

Pricing can be manifested in different forms, such as value-based (which is depending on the purchaser's perception on the speech therapy service offered), can be according to the market competitiveness and going-rate (for instance, if the market price is at standard rate, the pricing would be more or less at that range), skimming (which targets the affluent clients with families/children diagnosed with feeding, swallowing and communication problems), discount, loss-leader (purposefully set the price at a lower price than the market price in order to attract client crowd) and psychological (such as put the price at RM99 rather than RM100). Promotion could directly point out the significance of their advantages and their respective marketing positions (Chen, 2018). To strengthen the customer relationship with the brand, a promotion can deepen a client's memory towards the pricing structure and strategies set by a speech therapy centre.

Therefore, when promotion emphasizes the availability of early bird discount or credit term (price delivery), which can relieve purchasers' financial aspect in the long term, the brand loyalty could be maximized with the assistance of price promotion.

\subsection{Relationship between Marketing Mixture of Product Promotion and Brand Loyalty}

In speech therapy industry, product refers to the goods such as speech therapy 
handout, magazine, video or other (for sale), and refers to the service itself such as individual speech therapy and group speech therapy. The aspect which business owner should pay close attention in Product marketing is the function of the goods/service-whether the magazine and therapy can provide a sufficient amount of knowledge to the population; the appearance and design of the goods/service-whether the image of the educational video/service can attract the customer; the overall of goods-whether the bundle or the separate individual goods/service can fit to certain population.

Therefore, while marketing mix of product promotion place a special emphasis in the brand personality, which refers to the product itself, either in terms of value, presentation or mode, this type of marketing mix may positively affect the brand loyalty.

\subsection{Relationship between Marketing Mixture of Place Promotion and Brand Loyalty}

The places where promotion takes place affects quality of marketing and thus brand loyalty. A good promotion place improves the credibility of the store image and stimulates consumption growth (Chen, 2018). Speech therapy centre sourced continuous referrals or demand from different settings, hence those places required a different type of promotion. For instance, hospital would require feeding difficulty and therapy management information; nursery may instead require language difficulty and following therapy techniques-constituting proper type of promotional content at the proper channel/setting.

Therefore, when the promotion is done through several right places, it may promote brand loyalty in speech therapy industry.

\subsection{Relationship between Marketing Mixture of Product Price and Brand Loyalty}

Product Price would be taken in place when the speech therapy goods and service are assessed in terms of value, and either make it cost-plus (slightly above than the cost of production) or competitive (by aware to the price from competitors); and at the same time, working on the warranty, appearance and bundling of the product. The process of parents making decision for their children to engage in speech therapy includes the selection and evaluation of the price product/service, which assists the families or purchasers to make a wise decision.

Therefore, with enhanced marketing skill of product price, families get to know this element much better and hence, likely stimulates brand loyalty.

\subsection{Relationship between Marketing Mixture of Place Price and Brand Loyalty}

Price is an issue for customer in developing satisfaction toward healthcare service received. When they receive service expected from the amount of money invested, customer is more satisfied and be loyal to the brand (Rahman \& Osmangani, 2015). When Place Price are combined, this means the pricing about 
goods bundle, the payment method, the price flexibility, and other would be informed to customer through certain distribution channel(s). For instance, the speech therapy magazine would be seasonal, hence the pricing would be trade discounts for bulk purchase of speech therapy magazine or bundling of magazine and other speech therapy handouts. In this way, owner can detect market change, understand the client need by having face-to-face conversation.

Therefore, by intensifying marketing effort into Place Price, it could be beneficial to stimulate brand loyalty.

\section{Research Methodology}

Data collection will be conducted via distributing and collecting self-designed questionnaires to 200 respondents, who are the receivers of speech therapy service. The number of participants is kept at minimum of 200 in order to obtain statistical significance. Since the population of research is the receivers of speech therapy service, the ethical factor will be considered. Before filling up the questionnaire, researcher ensure the information provided by respondent is kept confidential. There was no name, email address, phone number section in the questionnaire and hence, researcher could not identify the participants. Participants are kept anonymous fully. Brand loyalty is measured using the adapted scale (Rubio et al., 2017). With a 7-point Likert scales, ranging from 1 (strongly disagree) to 7 (strongly agree), the data will be recorded. The principles of the questionnaire design is to list down the five independent variables (i.e. marketing $\mathrm{mix}$ ) and categorize the degree of brand loyalty into three different degree: "I am committed to purchasing from Grace House brand" (degree 1), "I would recommend Grace House brand to family and friends)" (degree 2), "I consider myself to be loyal to Grace House brand" (degree 3). With the apparent degree classification, researcher was able to detect the dependent variable or the outcome resulting from the marketing mix elements. Words were written in neutral tone and clear language. Data will be analyzed using Statistically Package for Social Science (SPSS) Version 18.0. Correlation analysis will be used to identify the correlation between the independent variables (i.e. marketing mix elements) and dependent variables (i.e. brand loyalty).

This study presents a framework which involves the relationship between independent variable and dependent variable. There are five independent variables, which are the mixture of any two marketing mix elements. There is only one dependent variable, which is the brand loyalty, specifically in speech therapy industry. The research framework is illustrated in Figure 1.

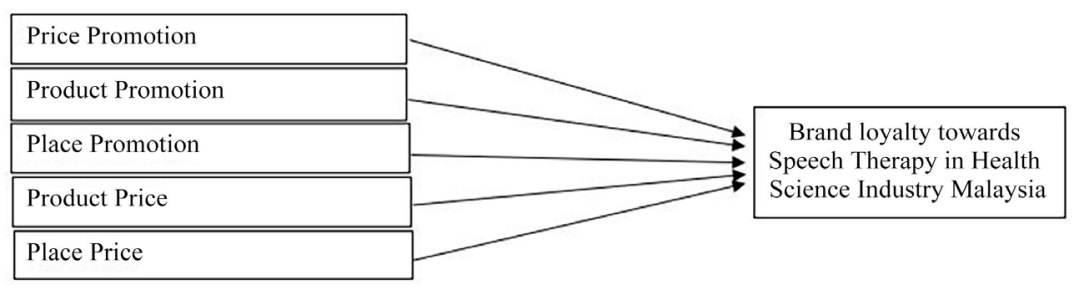

Figure 1. Research framework. 


\section{Research Hypotheses}

There are five hypotheses in this research:

H1: There is relationship between marketing mixture of Price Promotion and brand loyalty.

H2: There is relationship between marketing mixture of Product Promotion and brand loyalty.

H3: There is relationship between marketing mixture of Place Promotion and brand loyalty.

H4: There is relationship between marketing mixture of Product Price and brand loyalty.

H5: There is relationship between marketing mixture of Place Price and brand loyalty.

The way to verify the hypotheses is to conduct a test, which in form of survey. The analysis plan will be to accept or reject the hypotheses depending on the statistical result findings.

\section{Results and Discussion}

From the demographic characteristic shown in this research, $73 \%$ of respondents were female. $43 \%$ of respondents are at age of below 30 years old. $60 \%$ of respondents are Degree holders. $22.5 \%$ of respondents have average monthly income of RM3001-RM4000. 96.5\% of respondents accessed to brand product; $82.5 \%$ of respondents accessed to brand service. $59.5 \%$ of respondents know the brand from online platform.

Five hypotheses were discussed as shown below based on this study finding with support from the literature reviewed.

\subsection{There Is Relationship between Marketing Mixture of Price Promotion and Brand Loyalty}

$27 \%, 21.5 \%$ and $20 \%$ respectively of respondents mildly agree, moderately agree and strongly agree that they consider themselves to be loyal to Grace House brand due to Price Promotion. Based on the result of this research, the Pearson correlation coefficient between marketing mix of price promotion and brand loyalty is 0.861 which shows a very positive linear relationship between the two variables. There is significant relationship between marketing mix of price promotion and brand loyalty. This indicates that the increase of marketing mix of price promotion will increase the brand loyalty in speech therapy industry. This hypothesis is accepted.

A high price indicates a better quality of service, while a lower price fits better to the financial capacity of the families. Hence, both ends of pricing structures have its own advantages and thus serving different target populations with different socioeconomic backgrounds. When there is promotion about the pricing structure, either high price or low price, this could affect brand loyalty due to the condition of price comparison preference. For example, consistent therapy yields much effective therapy outcome, hence a continuous weekly or more frequent 
(let say, three times per week) session is recommended for standard practice. Meanwhile, parents may also need to do a huge amount of payment. With price promotion effect, they will be having heightened awareness at the beneficial payment period, trade discount, volume discount and wholesale pricing (for speech therapy product), bundling of services/products, and thus much willing to repurchase or revisit the specific brand.

\subsection{There Is Relationship between Marketing Mixture of Product Promotion and Brand Loyalty}

$27 \%, 23 \%$ and $23.5 \%$ respectively of respondents mildly agree, moderately agree and strongly agree that they consider themselves to be loyal to Grace House brand due to Product Promotion. Based on the result of this research, the Pearson correlation coefficient between marketing mix of product promotion and brand loyalty is 0.861 which shows a very positive linear relationship between the two variables. There is significant relationship between marketing mix of product promotion and brand loyalty. This indicates that the increase of marketing mix of product promotion will increase the brand loyalty in speech therapy industry. This hypothesis is accepted.

The purpose of promotion is to assist customers to understand the content of speech therapy, the idea of communication, the red flags of the child's communication delay and other relevant information. This marketing effort helps targeted individuals to satisfy their needs through purchase of goods and services. It can be in vary channels, such as radio, magazine, television and word of mouth. For product aspect, the warranty of the goods is important, such as when the magazine or book is received in not good condition, does the publisher/speech therapy owner will refund fully or provide another new magazine. In speech therapy industry, this is a significant marketing investment due to the low awareness of the public towards speech therapy services in Malaysia.

\subsection{There Is Relationship between Marketing Mixture of Place Promotion and Brand loyalty}

$27.5 \%, 18 \%$ and $23 \%$ respectively of respondents mildly agree, moderately agree and strongly agree that they consider themselves to be loyal to Grace House brand due to Place Promotion. Based on the result of this research, the Pearson correlation coefficient between marketing mix of place promotion and brand loyalty is 0.873 which shows a very positive linear relationship between the two variables. There is significant relationship between marketing mix of place promotion and brand loyalty. This indicates that the increase of marketing mix of place promotion will increase the brand loyalty in speech therapy industry. This hypothesis is accepted.

Place is an important attribute to the speech therapy rehabilitation journey. Child or adult clients require a fixed place for therapy, at a consistent rate. A change in place could invite anxiety and nervous in paediatrician and affects therapy effectiveness. Parents could display brand loyalty despite any degree of 
marketing effort from other brand to initiate brand shift. The coverage of the place could be manifested in three forms: intensive distribution, selective distribution and exclusive distribution. Market coverage may see the speech therapy owner to sell service at many places, such as provide speech therapy at many centres and schools, doing home visit speech therapy in many areas (intensive distribution); may see the speech therapists only target certain population such as only provide service to privileged places (selective distribution); may see certain speech therapists only accept cases in certain specialty such as feeding difficulties only and not speech and language difficulties cases (exclusive distribution). In terms of product and goods, the market coverage can be in such way: owner sells speech therapy magazine and handouts at many places including, for instance, 56 kindergartens in Kuala Lumpur, Johor, Pahang, Malacca (intensive distribution); owner (supplier) sells magazine and handouts only to 5 - 6 retailers (selective distribution) because they know these retailers get closer contact with targeted audience who in high need and are likely to purchase speech therapy magazine and handouts; owner may also choose to sell to only 1 retailer or reseller (exclusive distribution).

\subsection{There Is Relationship between Marketing Mixture of Product Price and Brand Loyalty}

$26 \%, 26.5 \%$ and $25.5 \%$ respectively of respondents mildly agree, moderately agree and strongly agree that they consider themselves to be loyal to Grace House brand due to Product Price. Based on the result of this research, the Pearson correlation coefficient between marketing mix of product price and brand loyalty is 0.857 which shows a very positive linear relationship between the two variables. There is significant relationship between marketing mix of product price and brand loyalty. This indicates that the increase of marketing mix of product price will increase the brand loyalty in speech therapy industry. This hypothesis is accepted.

In speech therapy industry, the product/service price had been a major consideration because engaging in a speech therapy is a continuous progress. For example, the speech therapy handout is sold at RM5 per set, due to the manpower wages, material and printing cost. The cost of production maybe RM3.50 per set, hence the handout is sold at RM5 with RM1.50 as the earning. The example for the Product would be to improve the quality and content of the speech therapy handout, either making it much reader-friendly by adding more layman term and explaining about the jargon. This works well if the bundle of goods are sold, such as purchase of 15 sets speech therapy handout (Product: bundle) will get 5\% discount (Price: discount), which includes the Price Product. This both $\mathrm{P}$ combination stimulate brand loyalty.

\subsection{There Is Relationship between Marketing Mixture of Place Price and Brand Loyalty}

$25 \%, 21 \%$ and $25.5 \%$ respectively of respondents mildly agree, moderately agree 
and strongly agree that they consider themselves to be loyal to Grace House brand due to Place Price. Based on the result of this research, the Pearson correlation coefficient between marketing mix of place price and brand loyalty is 0.873 which shows a very positive linear relationship between the two variables. There is significant relationship between marketing mix of place price and brand loyalty. This indicates that the increase of marketing mix of place price will increase the brand loyalty in speech therapy industry. This hypothesis is accepted.

When the places of price being distributed could differ, this would indirectly affect the brand loyalty. The location where the pricing structure had been targeted may contribute to positive or negative brand loyalty. For instance, when the banner about the affordable price was hanging at the physical speech therapy centre, this brings the passerby a heightened level of awareness of the pricing structure, hence achieving marketing effectiveness. Other than that, when reader who read magazine went through the advertisement of affordable pricing of the speech therapy service, it could affect customer decision. This includes the place price marketing coverage of social medias, such as Shopee, Facebook, Instalgram and YouTube, where the platforms which widely accepted and increasingly becomes popular among consumers. Speech therapy centre/store image combining with the pricing structure of the service or/and product (such as handout, book and others) would likely affect the brand loyalty.

\subsection{Reliability}

The analysis of this questionnaire in this study has Cronbach's alpha value of more than 0.7 for all 15 items in the scale. In fact, the scale had value of 0.963 . Hence, the research instrument was deemed to be reliable based on the alpha statistic.

\subsection{Correlation}

Brand loyalty of Price Promotion has $p=0.861$ with brand loyalty of Product Promotion. It means there is high positive linear relationship between brand loyalty, Price Promotion and Product Promotion.

Brand loyalty of Price Promotion has $p=0.784$ with brand loyalty of Place Promotion. It means there is high positive linear relationship between brand loyalty, Price Promotion and Place Promotion.

Brand loyalty of Price Promotion has $p=0.799$ with brand loyalty of Product Price. It means there is high positive linear relationship between brand loyalty, Price Promotion and Product Price.

Brand loyalty of Price Promotion has $p=0.820$ with brand loyalty of Place Price. It means there is high positive linear relationship between brand loyalty, Price Promotion and Place Price.

\section{Conclusion}

In conclusion, the marketing mix element stimulates the brand-customer attachment and promotes brand loyalty. For business/speech therapy centre owner, $t$ is 
vital to explore the non-clinical side, leveraging it with the clinical side in the pathway of brand building. The result is very much relevant to the entrepreneurs who keen to open speech therapy centre, as current trend would witness many freelancer speech therapists. This research supports the advantages of investing in the marketing skill in order to promote brand loyalty. Business owners are usually spending enormous resources in enhancing competitiveness. Now with the point of purchasers taken into consideration, business owners are advised to pay slightly more attention towards fruitfully influencing customer decision and behavior, fostering brand loyalty through right type of marketing mix in consideration of long-term brand building in the speech therapy industry in Malaysia.

The limitation of this study is that it doesn't take into consideration of the participants' type and number of services and/or products obtained. For instance, certain participants have accessed to only one type of service (i.e. tele-practice) but another may access to two types of service (i.e. tele-practice and centre visit). Certain participants may access to product and service (i.e. tele-practice and purchase speech therapy magazine). Since speech therapy places tremendous emphasis in the relationship between clinician/speech therapist and customer/parents and children, in future research, there is possibility for future researchers to investigate deeper on whether the marketing mix could affect customer experience, customer perception, therapy effectiveness or sustainable revenue, in order to achieve successful marketing. Other than that, they can focus more on Customer Relationship Management (CRM) in order to improve product/service awareness in speech therapy industry. Due to the nature of speech therapy which focus on client-therapist relationship, the CRM would be an important aspect and factor to build up brand loyalty. In fact, researcher can place more emphasis on the Integrated Marketing Communication (IMC) such as direct selling, mobile marketing, social media marketing, sales promotion and others, to investigate its role to build strong relationship with customers.

\section{Conflicts of Interest}

The authors declare no conflicts of interest regarding the publication of this paper.

\section{References}

Adel, P. (2015). The Impact of Marketing Mix Elements on Brand Loyalty: A Case Study of Mobile Phone Industry. Marketing and Branding Research, 2, 44-63. https://doi.org/10.33844/mbr.2015.60184

Chen, H.-J. (2018). What Drives Consumers' Mobile Shopping? 4Ps or Shopping Preferences? Asia Pacific Journal of Marketing and Logistics, 30, 797-815. https://doi.org/10.1108/APJML-08-2017-0167

Davcik, N. S., \& Sharma, P. (2015). Impact of Product Differentiation, Marketing Investments and Brand Equity on Pricing Strategies: A Brand Level Investigation. European Journal of Marketing, 49, 760-781. https://doi.org/10.1108/EJM-03-2014-0150

Jewel, D. N., Abubakar, J., Lucy, A., \& Samuel, D. (2018). The Effect of Branding on the Marketing Performance of Companies in the Mobile Phone Industry (Case Study of 
Techno Ghana, Accra). International Journal of Developing and Emerging Economies, 6, 39-60.

Malaysian Association of Speech-Language and Hearing (MASH) (2020). http://mash.org.my/

Odoom, R. (2016). Brand Marketing Programs and Consumer Loyalty_Evidence from Mobile Phone Users in an Emerging Market. Journal of Product \& Brand Management, 25, 651-662. https://doi.org/10.1108/JPBM-04-2016-1141

Rahman, M. S., \& Osmangani, A. M. (2015). Patient Satisfaction Constructs. International Journal of Health Care Quality Assurance, 28, 841-854.

https://doi.org/10.1108/IJHCQA-05-2015-0056

Rubio, N., Villaseñor, N., \& Yagüe, M. J. (2017). Creation of Consumer Loyalty and Trust in the Retailer through Store Brands: The Moderating Effect of Choice of Store Brand Name. Journal of Retailing and Consumer Services, 34, 358-368.

https://doi.org/10.1016/j.jretconser.2016.07.014

Tanford, S., Shoemaker, S., \& Dinca, A. (2016). Back to the Future: Progress and Trends in Hotel Loyalty Marketing. International Journal of Contemporary Hospitality Management, 28, 1937-1967. https://doi.org/10.1108/IJCHM-05-2015-0237

van der Westhuizen, L.-M. (2017). Brand Loyalty: Exploring Self-Brand Connection and Brand Experience. Journal of Product \& Brand Management, 27, 172-184.

https://doi.org/10.1108/JPBM-07-2016-1281 